Article

\title{
Rhodium Porphyrin Bound to a Merrifield Resin as Heterogeneous Catalyst for the Cyclopropanation Reaction of Olefins
}

\author{
Alina Ciammaichella, Valeria Cardoni, Alessandro Leoni and Pietro Tagliatesta * \\ Dipartimento di Scienze e Tecnologie Chimiche, University of Rome-Tor Vergata, Via della Ricerca Scientifica, \\ 00133 Rome, Italy; alina07@hotmail.it (A.C.); valery881@virgilio.it (V.C.); alessandro.leoni@uniroma2.it (A.L.) \\ * Correspondence: pietro.tagliatesta@uniroma2.it; Tel.: +39-6-7259-4759; Fax: +39-6-7259-4328 \\ Academic Editors: M. Graça P. M. S. Neves and M. Amparo F. Faustino \\ Received: 4 February 2016; Accepted: 24 February 2016; Published: 27 February 2016

\begin{abstract}
Cyclopropanation reaction is an important tool for obtaining interesting compounds and can be catalyzed by metalloporphyrins with high syn/anti ratio. The catalyst cannot be recycled and is usually lost during chromatographic separation from the two isomeric products. In this paper a meso-tetraphenylporphyrin rhodium(III) chloride was bound to a Merrifield resin and used to catalyze the cyclopropanation reaction of nine olefins, giving good yields and selectivities of the final products and for the first time, a partial recycling of the catalyst. This new catalytic system will be tested in the future for the synthesis of natural products containing cyclopropyl ring.
\end{abstract}

Keywords: porphyrin catalysts; cyclopropanation reactions; immobilized catalysts

\section{Introduction}

The cyclopropyl ring is an important organic function due to the presence of such structure in a number of interesting natural products. Recently, this ring has been found in molecules with antileukemic activity in vitro [1]. Several methods have been discovered in the past for obtaining such ring using copper, rhodium and osmium complexes as efficient catalysts for the synthesis of cyclopropanes from diazocompounds [2]. Synthetic iron, rhodium and osmium porphyrins have been also reported as catalysts for the cyclopropanation reaction of simple olefins by ethyldiazoacetate (EDA) [3-9]. Compared with the copper catalysts, like $\mathrm{CuCl}$ which preferentially affords the anti isomers, the porphyrin catalysts give interesting results in reversing the syn/anti ratio of the products depending on the nature of the metal. The reaction mechanism of the metalloporphyrins catalyzed cyclopropanation reactions is not completely elucidated in all the aspects, because of the lability of the bond between the central metal and the acetate residue.

However, the intermediate of the reaction, shown in Scheme 1, proposed, in the case of rhodium, by Callot et al. [10] was later studied by Kodadek, who used the NMR spectroscopy for detecting the possible carbene species [4]. 


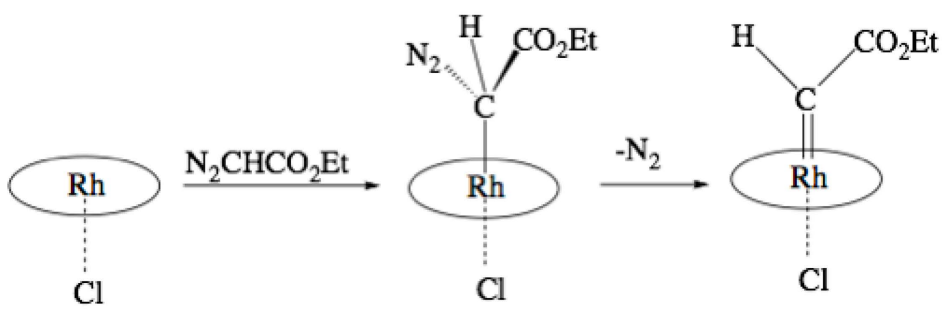

Scheme 1. Carbene formation mechanism.

During our studies on the catalytic properties of metalloporphyrins, we found that rhodium or ruthenium complexes of such macrocycles are able to catalyze the cyclooligomerization of arylethynes to give dimers or trimers, depending from the reaction conditions and substrates [11-15]. We also showed the possibility to bind a ruthenium porphyrin to the Merrifield resin to give an heterogeneous system able to catalyze the cyclooligomerization of alkynes with a complete recovery of the catalyst by simple filtration [16].

The recovering of the catalyst without any tedious column separation, is an important goal in preparative chemistry because this fact allows us to synthesize large amount of the products using small quantity of expensive metal complexes. In this paper we will show the possibility to use an immobilized metalloporphyrin as catalyst for the cyclopropanation of standard olefins, with good yields in some cases and high syn/anti ratios comparable with those obtained using normal metalloporphyrins in homogeneous solution [10].

\section{Results}

The heterogeneous catalyst was obtained by using the well known Merrifield technique [17] which was applied for the first synthesis of peptides in solid phase. The starting porphyrin free base, $\mathbf{1}$ was synthesized as reported in the literature [18] and rhodium complex $\mathbf{2}$ was obtained by a standard method [19]. After saponification with $\mathrm{KOH}$, the rhodium porphyrin 3 was bound to the solid resin using the Williamson method for the synthesis of ethers [20]. The synthetic steps are reported in Figure 1.

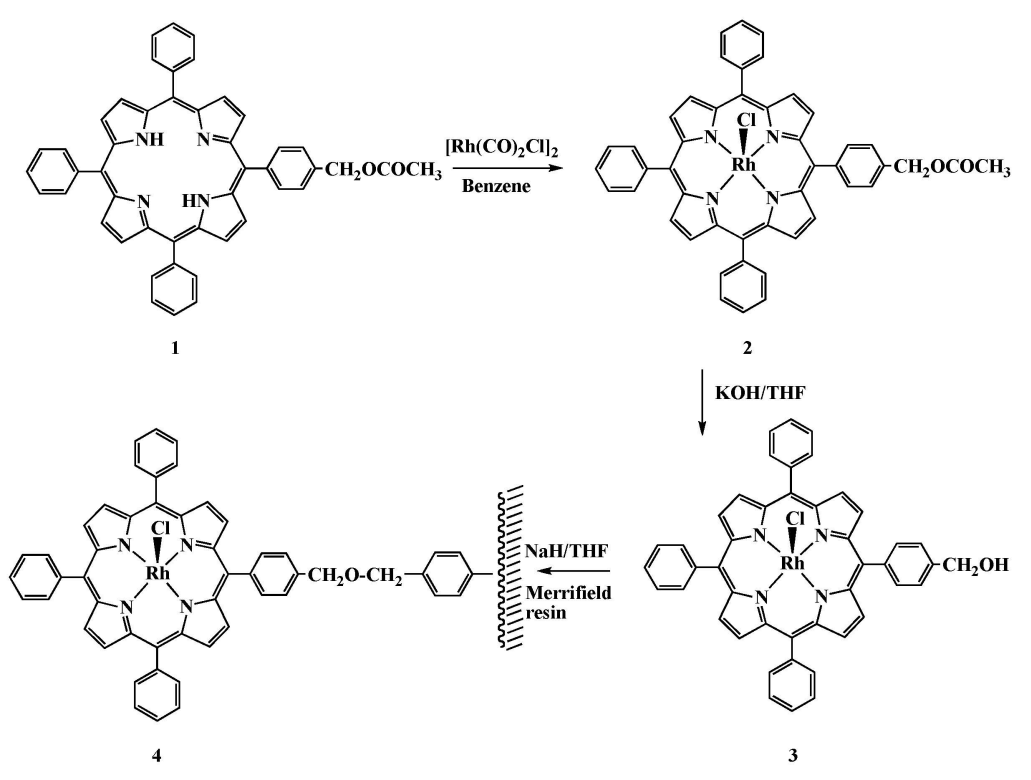

Figure 1. Synthetic pathway for obtaining the catalyst 4 . 
From the data of the elemental analysis obtained for the catalyst 4, we estimate the content of the rhodium porphyrin to be around 1 mmolar per gram of solid, a value very close to those obtained for other porphyrin functionalized solids [21-24]. The binding of the catalyst 3 to the solid through the ethereal function allows to separate the functionalized resin from the bulk of the reaction by vacuum filtration and reuse it.

Furthermore, the robustness of the system at the reaction temperature $\left(65^{\circ} \mathrm{C}\right)$ was also verified by $\mathrm{UV} / \mathrm{vis}$ methods. In fact after $48 \mathrm{~h}$ of reaction at this temperature no trace of free metalloporphyrin was detected in the reaction media by UV/vis spectra. In Table 1 we report the data obtained using nine simple olefins as substrates in the cyclopropanation reaction catalyzed by 4 . The catalytic activity of the rhodium porphyrin bound to the resin is compared with that obtained from literature (in parentheses) for styrene, cyclohexene and norbornene.

Table 1. Cyclopropanation of olefins catalyzed by 4 as catalyst compared with the data from previous papers.

\begin{tabular}{|c|c|c|c|c|}
\hline Entry & Substrate & Yield $(\%)^{b}$ & syn/anti Ratio $^{c}$ & syn/anti Ratio from Lit. ${ }^{d}$ \\
\hline 1 & Styrene ${ }^{a}$ & $60\left(71^{d}\right)$ & 1.12 & 1.13 \\
\hline 2 & 4-chlorostyrene & 55 & 1.10 & - \\
\hline 3 & 4-methylstyrene & 53 & 1.30 & - \\
\hline 4 & 4-methoxystyrene & 59 & 1.85 & - \\
\hline 5 & Cyclohexene ${ }^{b}$ & $48\left(62^{d}\right)$ & 1.03 & 0.84 \\
\hline 6 & Norbonene $\mathrm{b}^{\mathrm{b}}$ & $51\left(71^{d}\right)$ & 1.27 & 1.28 \\
\hline 7 & 1-Methylcyclopentene ${ }^{b}$ & $45^{\mathrm{e}}$ & $0.9^{\mathrm{e}}$ & - \\
\hline 8 & 2,4,4-Trimethylpentene ${ }^{a}$ & $70^{\mathrm{e}}$ & $0.72 \mathrm{e}$ & - \\
\hline 9 & trans- $\beta$-Methylstyrene $^{b}$ & 52 & 0.15 & - \\
\hline
\end{tabular}

a Reactions carried out at $65^{\circ} \mathrm{C}$ in $\mathrm{CHCl}_{3} \cdot{ }^{\mathrm{b}}$ Reactions carried out at $45^{\circ} \mathrm{C}$ in $\mathrm{CH}_{2} \mathrm{Cl}_{2}$ for $12 \mathrm{~h}$ with $3.7 \mathrm{mmol}$ of substrate and $20 \mathrm{mg}$ of catalyst $4 .{ }^{\mathrm{c}}$ Yields determined by GC analysis. ${ }^{\mathrm{d}}$ From ref. 10 with Rh(III)(TPP)I as catalyst. ${ }^{\mathrm{e}}$ This paper.

In our opinion these results support the fact that there is no influence of the polymeric matrix on the yields and syn/anti ratios.

\section{Discussion}

From the data it is clear that the yields of the reactions are slightly lower whilst the syn/anti ratios are comparable with those obtained using rhodium porphyrins in homogeneous solution. The turnover numbers are between $10^{3}$ and $10^{4}$ for all the reactions, much higher than those previously reported [10].

Only when cyclohexene is used as substrate the syn/anti ratio increases. The recycle of the catalyst did not give good results in the case of styrene which has been used as standard substrate. In fact the yield decreases to $42 \%$ in the second run but this value remains almost constant for the third and fourth run, showing that the catalyst retains part of its activity. It should be noted that to our knowledge, this is the first example of the reuse of a catalyst for the cyclopropanation reaction. Furthermore, the lower yield reported in the text for the reuse of the catalyst 4 after the first run, seems to be not much affected by the temperature. In fact a yield of 50\% for the reaction on styrene using 4 after a thermal treatment before the use, is almost comparable to that reported in Table 1 , entry 1. Control experiments were performed using catalyst 2 and 3 in homogeneous solution and 4 after treatment at $65^{\circ} \mathrm{C}$ in chloroform for $6 \mathrm{~h}$, using styrene as standard olefin. In Table 2 the results of such reactions are reported. In Supplementary Materials, experimental procedure and characterization of new compounds are reported. 
Table 2. Cyclopropanation of styrene catalyzed by 2, 3 and 4.

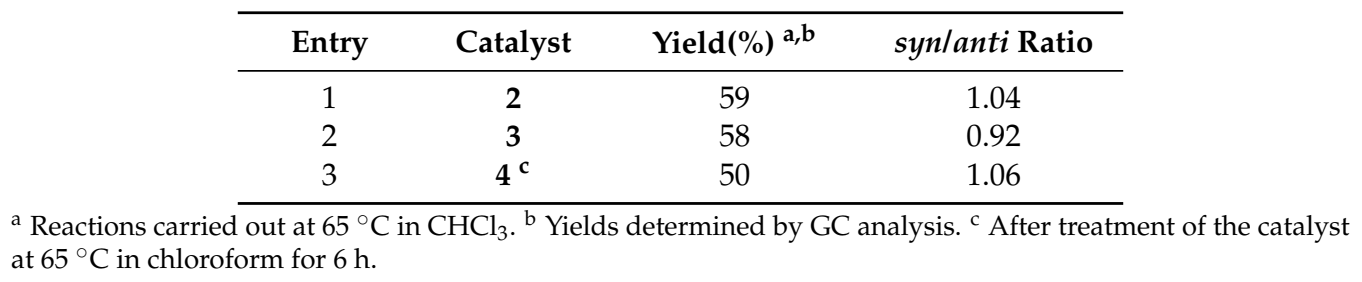

Both yield and syn/anti ratio for entries 1 and 2 are comparable with those obtained with catalyst 4 in the same experimental conditions (see Table 1, entry 1).

\section{Materials and Methods}

\subsection{General}

UV/vis spectra were recorded with a Varian Cary 10 spectrophotometer (Palo Alto, CA, USA). ${ }^{1} \mathrm{H}-\mathrm{NMR}$ spectra were recorded on a Bruker AM 400 spectrometer (Billerica, MA, USA) as $\mathrm{CDCl}_{3}$ solutions. Chemical shifts are given in ppm from tetramethylsilane (TMS) and are referenced against residual solvent signals. Mass spectra (FAB) were recorded on a VG-Quattro spectrometer (Fisons, Manchester, UK) using 3-nitrobenzylalcohol (NBA) as a matrix. The products yield and the isomeric ratios for all the reactions were determined by GC analyses (Waltham, MA, USA) performed on a Focus Thermo instrument equipped with a $15 \mathrm{~m}$ Restek MTX-5 capillary column and a FID detector. Chemical yields were determined by adding a suitable internal standard (decane or dodecane) to the reaction mixture at the end of each experiment and were reproducible within $\pm 2 \%$ for multiple experiments.

\subsection{Chemicals}

All the reagents and solvents (Aldrich, St. Louis, MO, USA) were of the highest analytical grade and used without further purification.

Silica gel 60 (70-230 and 230-400 mesh, Merck, Darmstadt, Germany) was used for column chromatography. High-purity grade nitrogen gas was purchased from Rivoira.

The free base 5-(4-acetoxymethylphenyl)-10,15,20-triphenylporphyrin was synthesized by literature methods [18].

Rhodium(III) meso-tetraphenylporphyrin chloride was obtained as reported in the literature. [19] Analytical data for cyclopropane derivatives of 4-chloro, 4-methyl and 4-methoxystyrene are reported in the literature [25].

\section{Conclusions}

In synthesis we have prepared a new heterogeneous catalytic system using a rhodium porphyrin immobilized on the Merrifield resin and used it for the cyclopropanation of nine standard olefins. The catalyst can be separated from the bulk of the reaction by a simple filtration and retains part of its catalytic activity. New studies on the use of similar strategies for obtaining heterogeneous porphyrin catalysts for other reactions are currently in progress.

Supplementary Materials: Supplementary materials can be accessed at: http://www.mdpi.com/1420-3049/ $21 / 3 / 278 /$ s1.

Author Contributions: Pietro Tagliatesta conceived and designed the experiments; Alina Ciammaichella and Valeria Cardoni performed the experiments; Alessandro Leoni contributed reagents/materials/analysis tools; Pietro Tagliatesta wrote the paper.

Conflicts of Interest: The authors declare no conflict of interest. 


\section{References}

1. Pogacic, V.; Bullock, A.N.; Federov, O.; Filippakopoulos, P.; Gasser, C.; Biondi, A.; Meyer-Monard, S.; Knapp, S.; Schwaller, J. Structural Analysis Identifies Imidazo[1,2-b]Pyridazines as PIM Kinase Inhibitors with in vitro Antileukemic Activity. Cancer Res. 2007, 67, 6916-6924. [CrossRef] [PubMed]

2. Doyle, M.P. Catalytic methods for metal carbene transformations. Chem. Rev. 1986, 86, 919-939. [CrossRef]

3. Robbins Wolf, J.; Hamaker, C.G.; Djukic, J.-P.; Kodadek, T.; Woo, L.K. Shape and stereoselective cyclopropanation of alkenes catalyzed by iron porphyrins. J. Am. Chem. Soc. 1995, 117, 9194-9199. [CrossRef]

4. Maxwell, J.L.; Brown, K.C.; Bartley, D.W.; Kodadek, T. Mechanism of the Rhodium Porphyrin-Catalyzed Cyclopropanation of Alkenes. Science 1992, 256, 1544-1547. [CrossRef] [PubMed]

5. Hamaker, C.G.; Djukic, J.-P.; Smith, D.A.; Woo, L.K. Mechanism of Cyclopropanation Reactions Mediated by (5,10,15,20-Tetra-p-tolylporphyrinato)osmium(II) Complexes. Organometallics 2001, 20, 5189-5199. [CrossRef]

6. Intrieri, D.; Caselli, A.; Gallo, E. Cyclopropanation Reactions Mediated by Group 9 Metal Porphyrin Complexes. Eur. J. Inorg. Chem. 2011, 2011, 5071-5081. [CrossRef]

7. Galardon, E.; le Maux, P.; Simonneaux, G. Cyclopropanation of Alkenes with Ethyldiazoacetate Catalysed by Ruthenium Porphyrin Complexes. Chem. Commun. 1997, 927-928. [CrossRef]

8. Tollari, S.; Gallo, E.; Musella, D.; Ragaini, F.; Demartin, F.; Cenini, S. Cyclopropanation of Olefins with Diazoalkanes, Catalyzed by CoII(porphyrin) Complexes-A Synthetic and Mechanistic Investigation and the Molecular Structure of CoIII(TPP)(CH2CO2Et) (TPP = Dianion of meso-Tetraphenylporphyrin). Eur. J. Inorg. Chem. 2003, 2003, 1452-1460.

9. Xu, X.; Lu, H.-J.; Ruppel, J.V.; Cui, X.; de Mesa, S.L.; Wojtas, L.; Zhang, X.P. Highly Asymmetric Intramolecular Cyclopropanation of Acceptor-Substituted Diazoacetates by Co(II)-Based Metalloradical Catalysis: Iterative Approach for Development of New Generation Catalysts. J. Am. Chem. Soc. 2011, 133, 15292-15295. [CrossRef] [PubMed]

10. Callot, H.J.; Metz, E.; Piechocki, C. Sterically crowded cyclopropanation catalysts. Syn-selectivity using rhodium(III)porphyrins. Tetrahedron 1982, 38, 2365-2369. [CrossRef]

11. Tagliatesta, P.; Floris, B.; Galloni, P.; Leoni, A.; D'Arcangelo, G. The First Solvent-free Cyclotrimerization Reaction of Arylethynes Catalyzed by Rhodium(III) Porphyrins. Inorg. Chem. 2003, 42, 7701-7703. [CrossRef] [PubMed]

12. Elakkari, E.; Floris, B.; Galloni, P.; Tagliatesta, P. The Formation of 1-Arylsubstituted Naphthalenes by an Unusual Cyclization of Arylethynes Catalyzed by Ruthenium and Rhodium Porphyrins. Eur. J. Org. Chem. 2005, 2005, 889-894. [CrossRef]

13. Conte, V.; Elakkari, E.; Floris, B.; Mirruzzo, V.; Tagliatesta, P. The Cyclooligomerization of Arylethynes in Ionic Liquids Catalysed by Ruthenium Porphyrins: A Case of Real Catalyst Recycling. Chem. Commun. 2005, 12, 1587-1588. [CrossRef] [PubMed]

14. Tagliatesta, P.; Elakkari, E.; Leoni, A.; Lembo, A.; Cicero, D. High Selective Biaryls Formation by the Cyclooligomerization of Arylethynes Catalyzed by Ruthenium and Rhodium Porphyrins. New J. Chem. 2008, 32, 1847-1849. [CrossRef]

15. Cicero, D.; Lembo, A.; Leoni, A.; Tagliatesta, P. The Highly Selective Formation of Biaryls by the Cyclization of Arylethynes Catalyzed by Vanadyl Phthalocyanine. New J. Chem. 2009, 33, 2162-2165. [CrossRef]

16. Ciammaichella, A.; Leoni, A.; Tagliatesta, P. Ruthenium porphyrin bound to a Merrifield resin as heterogeneous catalyst for the cyclooligomerization of arylethynes. New J. Chem. 2010, 34, 2122-2124. [CrossRef]

17. Merrifield, R.B. Solid Phase Peptide Synthesis. I. The Synthesis of a Tetrapeptide. J. Am. Chem. Soc. 1963, 85, 2149-2154. [CrossRef]

18. Paolesse, R.; Macagnano, A.; Monti, D.; Tagliatesta, P.; Boschi, T.J. Synthesis and Characterization of meso-Tetraphenylporphyrin-Corrole Unsymmetrical Dimers. J. Porphyrins Phthalocyanines 1998, 2, 501-510. [CrossRef]

19. Fleisher, E.B.; Lavallee, D. Phenylrhodium Tetraphenylporphine. Novel Synthesis of a rhodium-carbon sigma bond. J. Am. Chem. Soc. 1967, 89, 7132-7133. [CrossRef]

20. Baker, R.H.; Martin, W.B. A Side Reaction in the Williamson Synthesis. J. Org. Chem. 1960, 25, 1496-1498. [CrossRef] 
21. Battioni, P.; Bartoli, J.F.; Mansuy, D.; Byun, Y.S.; Traylor, T.G. An Easy Access to Polyhalogenated Metalloporphyrins Covalently Bound to Polymeric Supports as Efficient Catalysts for Hydrocarbon Oxidation. J. Chem. Soc. Chem. Commun. 1992, 15, 1051-1053. [CrossRef]

22. Hilal, H.S.; Kim, C.; Sito, M.L.; Schreiner, A.F. Preparation and Characterization of tetra(4-pyridyl)porphyrinatomanganese(III) Cation Supported Covalently on Poly(siloxane). J. Mol. Cat. 1991, 64, 133-142. [CrossRef]

23. Razenberg, J.A.S.J.; van der Made, A.W.; Smeets, J.W.H.; Nolte, R.J.M. Cyclohexene Epoxidation by the Mono-oxygenase Model (tetraphenylporphyrinato)manganese(III) acetate-sodium Hypochlorite. J. Mol. Cat. 1985, 31, 271-285. [CrossRef]

24. Zhang, J.-L.; Chan, P.W.H.; Che, C.M. Ruthenium(II) Porphyrin Catalyzed Cyclopropanation of Alkenes with Tosylhydrazones. Tetrahedron Lett. 2003, 44, 8733-8737. [CrossRef]

25. Galardon, E.; Le Maux, P.; Simonneaux, G. Cyclopropanation of Alkenes, N-H and S-H Insertion of Ethyl Diazoacetate Catalysed by Ruthenium Porphyrin Complexes. Tetrahedron 2000, 56, 615-621. [CrossRef]

Sample Availability: Samples of the all the reported compounds are available from the authors.

(C) 2016 by the authors; licensee MDPI, Basel, Switzerland. This article is an open access article distributed under the terms and conditions of the Creative Commons by Attribution (CC-BY) license (http://creativecommons.org/licenses/by/4.0/). 